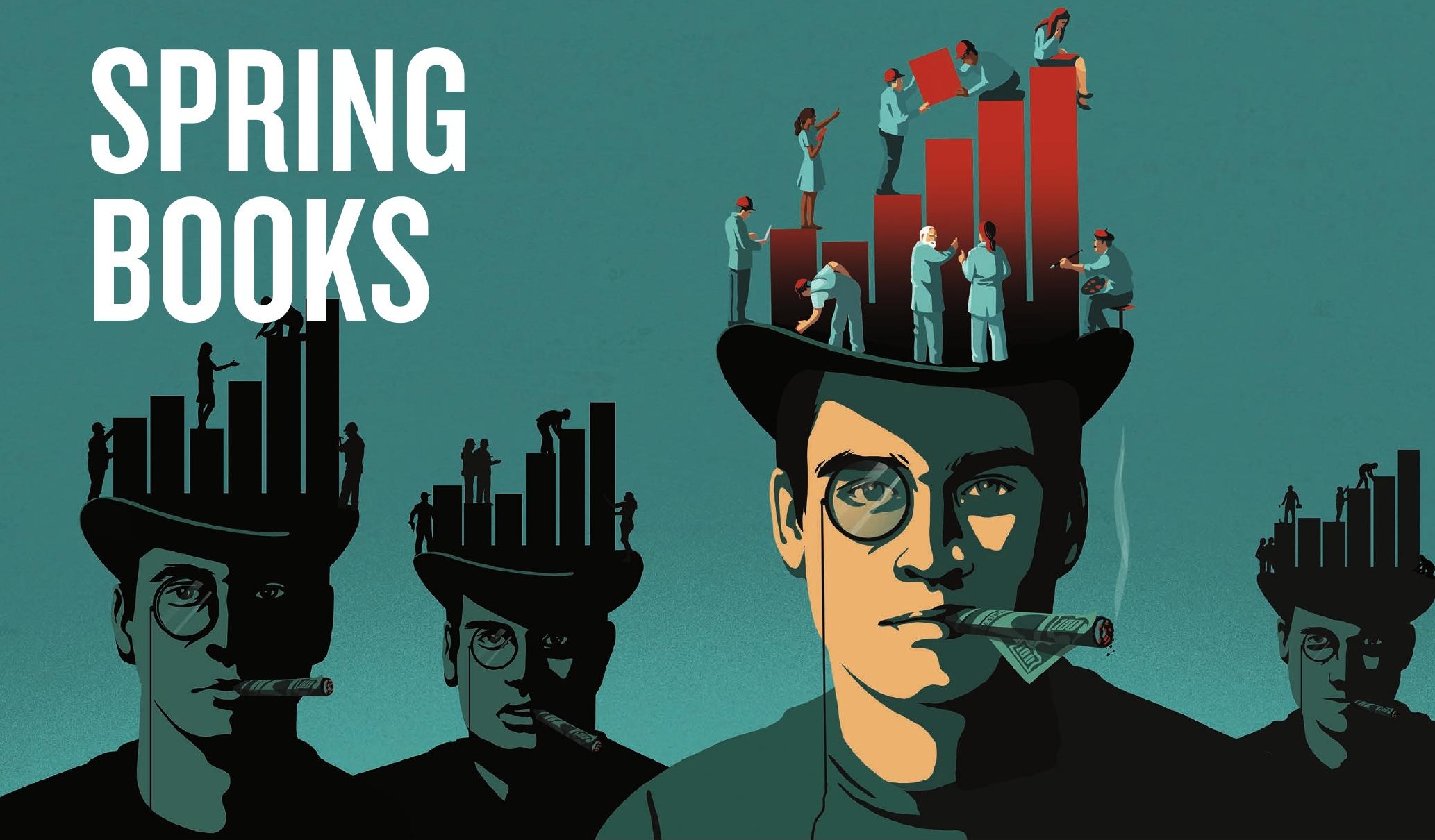

ECONOMICS

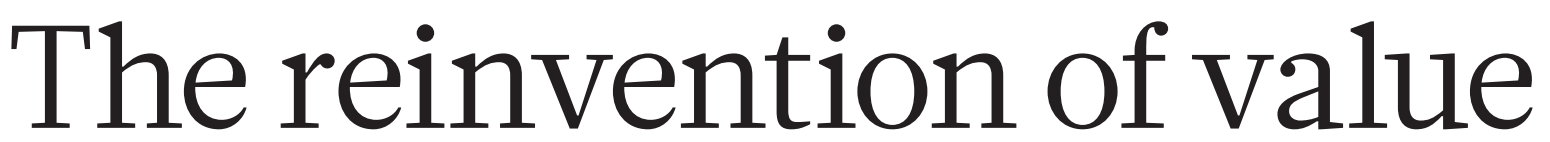

\author{
Robert Costanza applauds Mariana Mazzucato's call for more-productive, \\ equal and sustainable economies.
}

$\mathrm{W}$

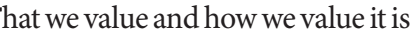
one of the most contested, misunderstood and important ideas in economics. Economist Mariana Mazzucato's comprehensive The Value of Everything explores how ideas about what value is, where it comes from and how it should be distributed have changed in the past 400 years, and why value matters now more than ever. Mazzucato emphasizes the need to reopen debate to make economies more productive, equitable and sustainable. The 2008 financial crisis was just a taste of looming problems climate disruption, massive biodiversity and ecosystem-services decline, even the possible collapse of Western civilization - unless we learn to value what really matters.

Early economists focused on the production of value from land (François Quesnay and the 'physiocrats'), labour (Adam Smith to Karl Marx) and capital. In this view, value determines price (Four decades ago, I described this in terms of embodied energy: see R. Costanza Science 210, 1219-1224; 1980). By contrast, the current mainstream 'marginalist' concept bases value on market exchanges: price, as revealed by the interaction of supply and demand in markets, determines value, and the only things that have value are those that fetch a price.

This has major implications for ideas about the distinction between value creation and value extraction, the nature

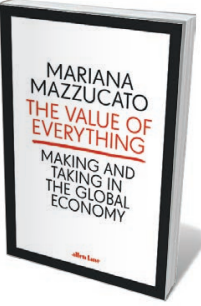

The Value of Everything: Making and Taking in the Global Economy MARIANA MAZZUCATO Allen Lane (2018)

of unearned income ('rent') and how value should be distributed. As Mazzucato notes, it stokes inequality because the market, simply by generating income, is seen to justify its level and distribution: "All income, according to this logic, is earned income: gone is any analysis of activities in terms of whether they are productive or unproductive."

Mazzucato lays out disturbing implications of the marginalist approach. These include (mis)measuring national income and real wealth, confusing financial speculation with the production of value, perverting the patent system (which stifles, rather than rewards, innovation) and undervaluing government and public goods, including public infrastructure, ecosystems and social networks. Her engaging and insightful exploration reveals how embedded the marginalist approach has become, and how it distorts economies' ability to foster innovation, equity and real progress.

The international System of National Accounts and gross domestic product (GDP) both value economic activity on the basis of market transactions - only goods and services sold in markets are counted. Much of that activity is beneficial, but some is best seen as a cost to be avoided. GDP conflates the two. For instance, growth of crime demands more police and security devices; these add to GDP, but more crime is not desirable. Increases in air and water pollution, serious illness and divorce are all counted as positive in GDP, whereas the distribution of income is ignored, 
as are the value of household and volunteer work, ecosystem services and community support. As economist and statistician Simon Kuznets, GDP's main architect, warned, a country's welfare cannot be inferred from GDP: "Goals for more growth should specify more growth of what and for what."

Mazzucato argues persuasively that GDP is a "hodge-podge" that "invites lobbying rather than reasoning about value". She notes that it "justifies excessive inequalities of income and wealth and turns value extraction into value creation". One alternative measure is the Genuine Progress Indicator (GPI), which attempts to separate environmental and social costs from benefits, to value household and volunteer work, and to adjust for inequality. For many countries, including the United States, China and the United Kingdom, there have been no net gains in GPI for several decades (I. Kubiszewski et al. Ecol. Econ. 93, 57-68; 2013). You get what you measure, and misusing GDP as a policy goal is distorting decisions about real progress (R. Costanza et al. Nature 505, 283-285; 2014).

Mazzucato deconstructs several other key trends. These include how the financial sector's "casino capitalism" mislabels market speculation as the creation of value rather than the mere extraction of value created elsewhere, and how the real value added by government and public goods and services have been ignored - to the detriment of us all. Ultimately, she notes, we need a more synthetic and integrative view: one that recognizes both how value is created and extracted in the current system, and how this needs to change. She concludes that value depends on vision: "If we cannot dream of a better future and try to make it happen, there is no real reason why we should care about value." The ability to value a healthy, sustainable planet, fairness, community and quality of life must be returned to the heart of economics.

Economics has been defined as the use of scarce resources to achieve desirable ends. In the Anthropocene epoch of human influence on the planet, we need to redefine those ends, and reevaluate which resources are truly scarce. Value should be viewed as contribution to the sustainable well-being of Earth and all its inhabitants. The United Nations Sustainable Development Goals are a huge step towards a broad global consensus on a desirable economy and society. As US baseball player Yogi Berra quipped: "If you don't know where you're going, you'll end up someplace else." Mazzucato's trenchant analysis is a compelling call to reinvent value as a key concept to help us achieve the world we all want.

Robert Costanza is a professor of ecological economics and Vice-Chancellor's Chair in Public Policy at the Crawford School of Public Policy of the Australian National University in Canberra.

e-mail:robert.costanza@anu.edu.au

\title{
COSMOLOGY
}

\section{The trouble with the Nobel prize}

\author{
Ron Cowen weighs up Brian Keating's call to reform \\ the most coveted award in physics.
}

I f cosmologist Brian Keating had his way, the scientific teams that made two of the most astounding discoveries in physics - the Higgs boson and gravitational waves - would never have won Nobel prizes.

It's not that Keating thinks the researchers undeserving. But the current rules and structure of the awards, he contends in Losing the Nobel Prize, foster ferocious and sometimes destructive competition for scarce research resources. He avers that the prizes are also biased against the work of female and younger scientists, and that they violate some of the very principles that Alfred Nobel, their founder, specified in his will more than a century ago.

Keating studies the infant Universe through subtle patterns in the cosmic microwave background (CMB) left over from the Big Bang. He is a deft writer, interweaving the science with personal musings on topics from his relationship with a father who abandoned him as a child to the passions that impel him to explore the unknown. Looming over all are his concerns about the Nobels.

These arose after his very public rollercoaster ride as part of a research team whose work briefly seemed a shoo-in for the physics prize. The team - a collaboration between institutions including the HarvardSmithsonian Center for Astrophysics (CfA) in Cambridge, Massachusetts, and the University of California, San Diego (UCSD) - had built two radio telescopes at the South Pole to hunt for a signature in the CMB that could reveal how the early Universe had evolved. Keating conceived the first, BICEP1. The team then developed the more sensitive BICEP2, which observed the CMB from 2010 to 2012.

Rumours of a scientific coup began flying in March 2014, even before the CfA alerted the media of an imminent "major discovery". The press briefing on 17 March did not disappoint (I was there, covering the event for Nature's news section). The team's four principal investigators, who included astronomer John Kovac, reported that they had detected a subtle twist in $\mathrm{CMB}$ polarization. They asserted that its source was almost

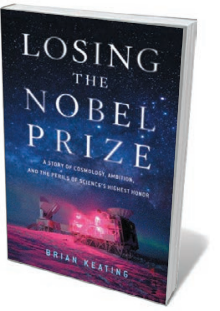

Losing the Nobel Prize: A Story of Cosmology, Ambition, and the Perils of Science's Highest Honor BRIAN KEATING

W. W. Norton (2018) certainly primordial gravitational waves, which would have been generated by inflation - a brief, faster-than-light ballooning of the infant Universe. That theoretical growth spurt had been a cornerstone of cosmology for some 35 years, but definitive proof had not been found.

BICEP2's discovery reverberated across the media. At the briefing, accolades poured in. Keating, one of several team members not there, recounts his mixture of frustration and elation: although Kovac mentioned his work, it was not cited in the press release. Keating well

knew that if a Nobel had been in the offing, he and most of the team would have been excluded, given the focus on principal investigators, and the rule that any prize can be shared by a maximum of three people.

The glory was, in any case, not to be. For months, Keating watched from the sidelines as the discovery literally turned to dust. All along, the BICEP2 team had worried that hydrocarbon soot and other cosmic particles could confound the results. (When light, including the CMB, reflects off nonspherical particles of galactic dust whose 